from species to species of tree ; these facts explain why it is that Lyctus attacks only certain kinds of timber and then only the sap-wood. The starch also varies in the growing tree from month to month, and is present in greatest abundance in winter, that is, in the felling season for 'hardwoods'.

It is found that if felled timber is kept ' in the log ' sufficiently long (about a year), the starch disappears entirely from the sap-wood, and such timber is proved to be immune to Lyctus infestation. If, however, timber is converted soon after felling and then quickly dried, as in kiln-drying or steaming, etc., the starch remains in the sap-wood and such timber is liable to damage; no subsequent (seasoning) treatment can remove the liability.

By seasoning susceptible species of timber "in the $\log$ " the pest can be controlled in a simple and inexpensive way, and its eradication from timber yards and wood-using factories is thus a practicable proposition. Damage costing many thousands of pounds a year can be saved and sap-wood made valuable, instead of being (as in oak) valueless for most purposes.

Royal Veterinary College,

S. E. WILSON.

Camden Town, N.W.1.

\section{Lunar Periodicity in Reproduction}

A NUMBER of living organisms, particularly marine animals, exhibit a lunar periodicity in reproduction. ${ }^{1}$ Tides do not seem to be a causal factor in this pheno. menon, and it has been difficult to understand how moonlight could be responsible, since the intensity of the light of the full moon is only about $1 / 500,000 t h$ that of sunlight.

Various authors in the past have pointed out that the light of the moon is partially polarised, and have suggested that polarised light is the responsible factor in lunar periodicity. This suggestion has been repeated in recent letters in NATURE. ${ }^{2,3}$ There are no known instances, however, of polarised light affecting organisms, and the little experimental work which has been done to test this has given negative results.4, 5 Moreover, animals and plants receive very much more polarised light from the sky during each day than they receive from the moon. The following approximate calculation makes this clear.

The area of the hemisphere of sky and the area of the full moon are respectively 20,627 and $0 \cdot 196$ square degrees. The intensity per unit area of the light of the full moon may be taken as being about five times the intensity per unit area of the light reflected from the day sky. Therefore,

$\frac{\text { Total flux from sky }}{\text { Total flux from full moon }}=\frac{20,627}{5 \times 0 \cdot 196}=2 \cdot 1 \times 10^{4}$.

The maximum polarisation of moonlight occurs at the first and third quarters, ${ }^{6}$ so that the maximum total amount of polarised light from the moon is received shortly after the first and before the third quarter. The light intensity of the full moon is about nine times that of half moon, so that

Total flux from sky

Total flux from half moon $=9 \times 2.1 \times 10^{4}=1.9 \times 10^{5}$.

The maximum percentage polarisation of moonlight ${ }^{6}$ is 9. The maximum percentage polarisation of light from the day sky is 85 , and applies to the light coming from the sky $90^{\circ}$ from the setting sun. ${ }^{7}$ Taking a value so low as one per cent for the polarisation of light from the sky during the day, we get :

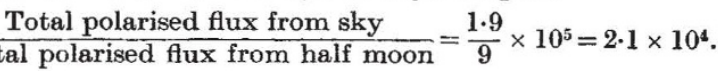
It is evident, therefore, that very much more polarised light is incident on the earth during the daytime than on moonlight nights.

Moreover, even if the polarised light of the moon could cause a reproductive rhythm, this would be a bilunar, not a lunar, cycle, for the maximum polarisation is at the first and third quarters.

Recent experimental work, 8,9 however, on the influence of light on sexual periodicity in general, suggests a way in which moonlight might impose a lunar periodicity. In mammals and birds the length of the breeding season appears to depend in part on the daily number of hours during which the animals are exposed to light. Thus the moon may perhaps cause a lunar cycle in reproduction, not through its relatively small intensity of light as compared with that of the sun, but by the additional total number of hours of illumination per 24 hours at full moon, over and above a threshold light value. Only experimental work can test this hypothesis.

H. Munro Fox.

Zoological Department,

University of Birmingham, June 3.

1 Fox, Prac. Roy. Soc., B, 95, 523 ; 1923.

2 Cunningham, N ATURE, 129, 543, April 9, 1932

3 Philip, NatuRe, 129, 655, April 30, 1932.

4 Crozier and Mangelsdorf, J. Gen. Physiol., 6, 703 ; 1924

s Naviez and Rubenstein, J. Biol. Chem., 80, 503; 1928.

- Lyot, C.R. Ac. Sc., 178, $1796 ; 1924$.

$?$ Tichanowsky, Phys. Z., 28, $252 ; 1927$.

- Baker and Ranson, Proc. Roy. Soc. B, 110, 313; 1932

- Bissonnette, Proc. Roy. Soc., B, 110, 322 ; 1932.

\section{A Genus of Ranunculaceæ hitherto Unrecorded} for New Zealand

Dr. W. A. Sledge, of the University of Leeds, who has recently brought home from New Zealand a collection of dried plants, kindly allowed me to look through his surplus stock of species belonging to Ranunculus and to take what flowers I liked for examination, as I am especially interested in the petal of this genus. One species, Ranunculus tenuicaulis Cheesem., appealed to me particularly on his information that he had noticed it when growing to have reddish flowers. Red colouring is unusual among buttercups.

On soaking out the two flowers available, I found on investigation that there was no sign of a double perianth. Thinking possibly that the sepals might have fallen, as these flowers were fully mature, Dr. Sledge supplied me with younger ones from his mounted sheet. These likewise showed a simple (monoseriate) perianth. Further, there was no indication of any nectary on the perianth segment or tepal, to use a non-committal term. The petal of Ranunculus is invariably characterised by the possession of such. The perianth, then, of this interesting plant is probably a petaloid calyx of five sepals. The small flower is borne singly on a short stalk arising from a whorl of three somewhat foliaceous bracts suggestive of the involucre of Anemone. The carpel is of a type quite unusual for Ranunculus, having a long spirally recurved style. The material at my disposal has scarcely been sufficient to ascertain definitely as to the exact manner in which the ovule is borne, but such evidence as has been obtained points strongly to a suspended rather than a basally attached one. Dr. Sledge has since satisfied himself that the ovule is suspended.

The examination of these flowers, then, certainly rules out Ranunculus as the genus to which this plant belongs, and suggests that the Ranunculus tenuicaulis of Cheeseman may be a species of Anemone. At any rate, it is a member of a Ranunculaceous genus hitherto unrecorded for New Zealand. So far, the only genera of this attractive family occurring in these islands are Ranunculus itself, by far the largest

$$
\text { No. } 3270 \text {, VoL. 130] }
$$

